\title{
GANGUES, PICHAÇÕES E FACÇÕES: \\ EVOLUÇÃO E CONFIGURAÇÃ̃ GEOGRÁFICA DOS TERRITÓRIOS DO TRÁFICO DE DROGAS NA PERIFERIA DE BELÉM
}

\author{
GANGS, PICKS AND FACTIONS: \\ EVOLUTION AND GEOGRAPHICAL CONFIGURATION OF DRUG \\ TRAFFICKING TERRITORIES IN BELÉM'S OUTLYING GHETTOS
}

Aiala Colares Couto ${ }^{1}$

\section{Resumo}

Os territórios do narcotráfico na periferia de Belém são resultados de relações e de articulações que foram construídas ao longo das décadas e que envolveram uma evolução das gangues de rua às facções do crime. São territórios que se sobrepõem, inclusive, em espaços de resistência da ocupação urbana. Assim, Belém conta com a organização de duas formas de territórios relacionados a esta atividade. O objetivo deste artigo é analisar a formação dos territórios-rede e dos territórios-zona do narcotráfico. A metodologia da pesquisa teve como foco os trabalhos de campo com observações e entrevistas, registros fotográficos, pesquisa bibliográfica e análise documental que possibilitaram, de maneira geral, a interpretação teórico-empírica deste trabalho. Por fim, escolher o narcotráfico como tema de investigação científica parte da necessidade de explicações acerca da dinâmica social, política e econômica que ele impõe, sobretudo, nas áreas historicamente negligenciadas pelas políticas públicas e pelas políticas urbanas destinadas para a metrópole.

Palavras-Chave: Narcotráfico. Facções. Redes. Territórios. Periferias.

\begin{abstract}
The drug trafficking territories on Belém's outlying ghettos are the result of relationships and articulations that were built over the decades and that involved the evolution that went from street gangs to criminal factions. These are overlapping territories, moreover in spaces of resistance to urban occupation. Thus, Belém has two forms of territories' organization related to this activity. The purpose of this article is to analyze the formation of territories' networks and zone territories for drug trafficking. The research's methodology was focused on fieldwork with observations and interviews, photographic records, bibliographic research and documentary analysis that enabled, in general, the theoretical-empirical interpretation of this work. Finally, choosing drug trafficking as a theme a scientific research comes from the need for explanations about the social, political and economic dynamics that it imposes, especially in areas historically neglected by public policies and urban policies destined for the metropolis.
\end{abstract}

Keywords: Drug trafficking. Factions. Networks. Territories. Ghettos.

\footnotetext{
${ }^{1}$ Geógrafo pela Universidade Federal do Pará e Doutor em Ciências do Desenvolvimento Socioambiental (NAEAUFPA). Professor do curso de Geografia da Universidade do Estado do Pará (UEPa). E-mail: aialacolares@ hotmail.com 


\section{DAS GANGUES DE RUAS ÀS FACÇÕES: PROCESSOS DE FORMAÇÃO E EVOLUÇÃO DOS TERRITÓRIOS DO NARCOTRÁFICO NAS PERIFERIAS DE BELÉM}

A compreensão acerca do narcotráfico, sobretudo o narcotráfico territorializado nas periferias de Belém, só é possível se entendermos os processos que levaram a tais configurações geográficas, que têm nas relações de poder estratégias que constituem o domínio do território. De antemão, destaca-se que a análise empírica que fez parte da metodologia de pesquisa que resultou neste texto analisou o processo de evolução política, econômica e cultural do fenômeno do narcotráfico. Nesse sentido, podemos observar três fases dessa construção: a primeira delas data os anos de 1980 e início dos anos de 1990, definida aqui como fase embrionário do tráfico de drogas nas periferias de Belém, tendo como modelo de comércio/varejo as chamadas "bocas de fumo", e o principal ilícito era a maconha comercializada em pequenos cartuchos; a segunda fase ocorre na metade dos anos de 1990 e vai até mais ou menos o ano de 2006, é a chamada fase de expansão do tráfico de drogas, quando as antigas gangues de rua compostas por pichadores passam a ser cooptadas por traficantes, nesse período, temos a entrada no mercado da pasta de base de cocaína conhecida como "nóia" ou "mesclado" , e alguns jovens da periferia serão selecionados para exercer o papel de aviãozinhos ${ }^{4}$ e olheiros $^{5}$ do tráfico, podemos dizer que é o início da construção dos territórios; e uma terceira fase a partir de 2007 em que se define como fase de consolidação do tráfico de drogas, pois ocorre nesse momento a extinção das gangues de pichadores e em sua substituição surgem as facções do tráfico de drogas ${ }^{6}$ em Belém, agora organizadas em territórios em que existiram essas gangues ${ }^{7}$. É o momento de popularização da cocaína em pó que rapidamente se torna uma droga expressiva no mercado da cidade, atingindo todas as classes sociais.

Por isso, a terceira fase é considerada a mais importante nesse momento, pelo fato de construir as bases para a integração de Belém em um circuito espacial em redes de distribuição de cocaína na Amazônia. Assim, quando analisadas as formas ou demonstrações de poder do narcotráfico a partir das definições dos territórios, observa-se, então, o papel de destaque que as pichações exercem diante do contexto de produção simbólica do

\footnotetext{
${ }^{2}$ Em Belém, nos anos de 1990, as chamadas "bocas de fumo" eram como denominavam-se os locais onde as pessoas dirigiam-se para comprar maconha. Em algumas "bocas", também podia ser permitido o consumo em lócus. Elas ainda existem, porém, não obedecem mais a esse modelo antigo de comercio/varejo da droga.

${ }^{3} \mathrm{O}$ mesclado é como chamam para a mistura da maconha com a pasta de base de cocaína que é fumada como cigarro. Há também a possibilidade da mistura do tabaco com a cocaína em pasta. É uma droga que nesse período passa a ser consumida de forma intensa e concentrada nas periferias de Belém.

${ }^{4}$ São os sujeitos encarregados de vender a droga para os consumidores.

${ }^{5}$ São os sujeitos que se encarregam de observar o movimento de moradores e da polícia na zona de controle do narcotráfico.

${ }^{6}$ Esses grupos se denominam facções do narcotráfico em substituição ao termo gangues, contudo, algumas ainda utilizam em suas siglas a palavra "Equipe”, podendo ser encontrado também o termo "Galera".

${ }^{7}$ Os anos de 1990 em Belém foi marcado pela existência de várias gangues de pichadores distribuídas espacialmente pelos bairros periféricos. Cada gangue tinha um símbolo e seu território que era demarcado por pichações. A primeira gangue de Belém foi a Bailique que dominava a área da Campina, Batista Campos e Nazaré, era composta por jovens de classe média e surgiu na segunda metade dos anos de 1980 sendo extinta no final da mesma década e tinha como inspiração as gangues de Nova Yorque nos EUA.
} 
controle do espaço. Além disso, essa relação simbólica com o tráfico de drogas, que se dá a partir das periferias, está diante de uma outra relação que é a afirmação das facções do narcotráfico.

“Equipes” ou facções são os grupos de sujeitos envolvidos nas redes do tráfico de drogas e que através das pichações demarcam áreas geográficas dentro dos bairros para definir suas zonas de ação. Essas práticas podem ser definidas por Haesbaert (2004) como uma espécie de apropriação simbólico-cultural, acompanhada por uma dominação político-econômica dos territórios.

A dominação político-econômica está no sentido de atribuir um valor econômico ao território, e este valor surge em função do comércio de cocaína, principalmente em zonas definidas pelos grupos em pontos estratégicos dos bairros. Consideram-se pontos estratégicos aqui, como os locais onde ao mesmo tempo em que existe a facilidade para os fluxos de consumidores deve haver também facilidade para que aviãozinhos possam escapar das investidas das polícias ou de ataque de grupos rivais. Além disso, a apropriação simbólicocultural não está apenas na representação dos símbolos que são desenhados nas paredes destacando a presença das "Equipes" ou facções do tráfico de drogas, mas também está em uma relação construída cotidianamente pelos seus sujeitos. Nesses termos, o narcotráfico produz seus códigos, seus símbolos e suas linguagens em forma de gírias identificáveis apenas por membros dos seus grupos.

É importante também saber que esta relação descrita acima é muito mais presente nas periferias ou nas áreas de baixadas ${ }^{8}$ de Belém. Este comportamento foi identificado nos bairros como: Terra Firme com a "Equipe Rex", "Equipe Pernal" e a "Liga da Justiça". No bairro do Jurunas, isso ocorre com a "Galera da Laje, na Cabanagem com os "Mirienses" e a "Equipe do Dote", dentre outras. É importante apresentar estes grupos, pois foram as "Equipes" ou facções que mais chamaram a atenção pelo nível de organização e movimentação que realizam nos bairros citados. E esse movimento tem como pano de fundo o mercado da droga que promove também os conflitos armados.

Os três bairros citados são considerados bairros da periferia de Belém, porém com uma diferença em seus processos históricos de formação, por exemplo, O Jurunas teve o seu processo de ocupação iniciado nos anos de 1940, em que grande parte da população desse bairro migrou do interior do estado do Pará e das regiões das ilhas de Belém, já o bairro da Terra Firme tem sua origem a partir dos anos de 1950 com um intenso processo de ocupação que se dá em terras que pertenciam ao cinturão institucional de Belém. Os dois bairros estão localizados na zona Sul de Belém e são considerados de áreas de baixada, sofrendo com alagamentos constantes - principalmente durante o inverno chuvoso. Do outro lado, na zona Leste, o bairro da Cabanagem está relacionado ao crescimento urbano e populacional de Belém a partir dos anos de 1980, ele corresponde à

\footnotetext{
${ }^{8}$ Define-se como baixadas as áreas formadas por planícies de inundação e terras alagáveis da Primeira Légua Patrimonial. O relatório técnico da SUDAM, conhecido como monografia das baixadas de Belém, utilizou como critério para tal definição as terras alagáveis situadas abaixo da cota altimétrica de 4,0 m. São os locais densamente ocupados que formam os bairros populares próximos ao centro de Belém. Esses terrenos foram a opção de moradia e de luta da população de baixa renda pelo direito à moradia.
} 


\section{Gangues, pichações e facções: \\ Evolução e configuração geográfica dos territórios do tráfico de drogas na periferia de Belém}

segunda fase de expansão urbana da cidade. De toda forma, esses três bairros citados sofrem com problemas de infraestrutura urbana como: saneamento básico, tratamento de água potável, tratamento de esgoto, coleta de lixo, dentre outros.

Para Haesbaert (2004), apesar de ser uma categoria central para a Geografia, território e territorialidade, por dizerem respeito à espacialidade humana, têm uma certa tradição também em outras áreas, cada uma com enfoque centrado em uma determinada perspectiva e o geógrafo tende a enfatizar a materialidade do território, em múltiplas dimensões (que deve(ria) incluir a interação sociedade-natureza).

Assim,

a Ciência Política enfatiza sua construção a partir de relações de poder (na maioria das vezes, ligada à concepção de Estado); a Economia, que prefere a noção de espaço à território, percebe-o muitas vezes como um fator locacional ou como uma das bases da produção (enquanto "força produtiva"), a Antropologia destaca sua dimensão simbólica, principalmente no estudo das sociedades ditas tradicionais (mas também no tratamento do "neotribalismo" contemporâneo); a Sociologia o enfoca a partir de sua intervenção nas relações sociais, em sentido amplo, e a Psicologia, finalmente, incorpora-o no debate sobre a construção da subjetividade ou da identidade pessoal, ampliando-o até a escala do indivíduo (HAESBAERT, 2004, p. 37).

Embora o território não seja uma categoria exclusiva da Geografia, ela é a Ciência que melhor explica essas múltiplas dimensões que produzem certas territorialidades para além da visão estadocentrica ou puramente econômica sobre a projeção política da sociedade sobre o espaço, mas não deixando jamais de considerar as relações de poder que os definem. É logico que estamos diante de uma atividade na qual necessita ter o controle efetivo de uma área geográfica, porém quando se trata de um aprofundamento empírico sobre a problemática do narcotráfico em Belém, vamos visualizar uma mudança na estrutura organizacional que ocorre no período de 2012 a $2016 .{ }^{9}$

Em Belém, encontram-se tipos zonais de territórios definidos a partir do controle de porções do espaço urbano que estão sob as relações de poder do tráfico de drogas. Esses territórios constituídos nos bairros da periferia transformam-se de zonas conectadas em uma lógica reticular ou organizacional que são estabelecidas na região amazônica a partir do crime organizado, que transforma a metrópole em uma espécie de "nó" ou nexo de sua estrutura espacial regional-global.

Haesbaert (2004 p. 40) faz uma síntese das várias noções do conceito de território, na qual agrupa estas concepções em três vertentes: a política, a cultural e a econômica. Com essas vertentes destacadas pelo autor, temos a concepção por ele definida como dominação político-econômica e apropriação simbólico-cultural. A territorialidade é da natureza humana, mas o autor chama a atenção para a dimensão "natural” do território, visto que também essa categoria vem da ecologia para entender o mundo animal.

\footnotetext{
${ }^{9}$ Mudança essa observada durante as pesquisas de campo com observações sistemáticas, entrevistas e coleta de dados, metodologia utilizada para o desenvolvimento da tese de doutorado defendida em 2017 no Programa de Pós-Graduação em Desenvolvimento Sustentável do Trópico Úmido - PPGDSTU-NAEA-UFPA.
} 
Voltaremos para a perspectiva teórico-empírica deste artigo. Dessa forma, buscando demonstrar as geo-grafias que o tráfico de drogas constrói na cidade, usa-se o termo geo-grafias com o duplo sentido, posto que o primeiro está associado ao sentido de produção do espaço, e o segundo sobre as marcas ou grafias criadas pelo tráfico de drogas no espaço. Em Belém, tráfico de drogas e pichações estão intimamente relacionados. Como vimos, grupos de pichadores integrantes gangues de rua foram inseridos na organização da rede social criada e condicionada pela economia do crime. As antigas brigas ou confrontos entre gangues de pichadores deram lugar aos conflitos armados entre sujeitos e facções rivais do narcotráfico.

Em alguns bairros, as antigas gangues rivais deixaram as diferenças de lado e passaram a fazer parte de uma relação mais ampla sob a influência do narcotráfico. Em outras palavras, houve uma inserção delas no circuito territorial do narcotráfico, a exemplo do que aconteceu no Jurunas, Cremação e Guamá. Porém, no bairro da Terra Firme, as gangues mesmo incorporadas à lógica do tráfico com o surgimento de facções ainda se mantiveram em conflitos por um tempo, nesse caso, na região do bairro denominada de área do Tucunduba ${ }^{10}$ considerado um corredor intraurbano de abastecimento do mercado da droga. Assim, as facções denominadas Equipe Rex e Liga da Justiça ${ }^{11}$ transformaram essa parte do bairro em um espaço de disputas pelo controle e domínio das bocas de fumo e de uma das principais rotas da cidade.

Nos bairros do Benguí e do Barreiro, as gangues também foram rapidamente absorvidas pelo narcotráfico, ocorrendo o mesmo na Cabanagem, onde cederam lugar às facções do tráfico de droga da Galera do Dote ${ }^{12}$ e dos Mirienses. No bairro do Tenoné, tem a famosa invasão do Tocantins, e no Distrito de Icoarací na porção mais Norte de Belém, tem-se: Uxiteua e Mangue no bairro da Campina, as áreas conhecidas como Cobrolância e Fazendinha no Paracurí I, Buraco Fundo fica no Paracurí II. Todas essas áreas destacadas em Icoarací contam com a presença do tráfico de drogas e foram lugares que no passado contavam com a presença de gangues de ruas.

Nesses espaços, formam-se redes sociais do tráfico de drogas, constituídas por jovens que são facilmente levados para o "lado perverso" da economia do crime, e isso envolve um conjunto de relações sociais. A sociologia define "rede" como um conjunto de relações sociais entre um conjunto de atores e entre os próprios atores. Segundo Colonomos (1995), designa ainda os movimentos pouco institucionalizados,

\footnotetext{
${ }^{10}$ A área do Tucunduba é como popularmente os moradores do bairro definem a região de entorno do rio Tucunduba que entra no bairro da Terra Firme e Guamá. Para os moradores, o rio ou igarapé do Tucunduba é considerado o limite entre um bairro e outro.

${ }^{11}$ A Equipe Rex e a Liga da Justiça foram facções que disputaram o controle da área do Tucunduba no período de 2007 a 2010. A primeira resultou da antiga gangue dos Invasores da Passagem Ligação, e a segunda é da união entre as gangues Ratos Demolidores da rua Lauro Sodré e da Falange Vermelha da rua São Domingos. Essas informações foram coletadas durante a pesquisa de campo que deram origem à dissertação de mestrado intitulada "Narcotráfico na metrópole: redes ilegais à territorialização perversa ne periferia de Belém”. Trabalho defendido em 2010 no Programa de Pós-Graduação em Planejamento do Desenvolvimento (PLADES-UFPA).

${ }^{12}$ Depois da prisão do traficante de drogas conhecido como Dote, em 2012, o bairro da Cabanagem passou a sofrer com conflitos envolvendo o controle do comércio/varejo de drogas, onde o grupo conhecido popularmente como Mirienses passou a exercer o controle de parte do bairro. Além disso, a Cabanagem também passou a conviver com a existências de milicianos que controlam serviços de transportes clandestinos de vans e moto taxis.
} 
reunindo ou grupos numa associação cujos limites são variáveis e sujeitos a reinterpretações. Os antropólogos irão a partir da noção de redes buscar apoiar "a análise e descrição daqueles processos sociais que envolvem conexões que transpassam os limites de grupos e categorias" (BARNES, 1987, p. 163).

Essas áreas de vulnerabilidade social (ou espaços precários em relação à presença do poder público) tendem a conviver com a existência de vários conflitos sociais: violência contra a mulher, violência contra o idoso, famílias desestruturadas, exploração sexual infantil, tráfico de drogas, alcoolismo, dentre outros. São problemas que comprometem a qualidade de vida da população e atingem, sobretudo, os mais jovens que diante das precariedades em relação aos serviços de educação, saúde, esporte, lazer, habitação e saneamento básico, têm sua rede social comprometida e essa realidade cotidiana leva-os a procurarem alternativas de sociabilidade na busca constante de negar a exclusão. Assim, muitos jovens das periferias se integraram às gangues e posteriormente, às redes do tráfico de drogas ou outras atividades criminosas. A tabela 01 abaixo destaca as principais gangues dos anos de 1990 nos bairros e no distrito que vêm se destacando em função das atividades do narcotráfico.

Tabela 1 - Bairros e Gangues de Belém anos de 1990

\begin{tabular}{|l|l|l|}
\hline \multicolumn{1}{|c|}{ BAIRRO/GANGUES } & \multicolumn{1}{c|}{ BAIRRO/GANGUES } & \multicolumn{1}{c|}{ BAIRRO/GANGUES } \\
\hline BARREIRO & \multicolumn{1}{c|}{ BENGUÍ } & \multicolumn{1}{c|}{ CABANAGEM } \\
\hline Ratos do Barulho & Armação & Galera do Costa e Silva \\
\hline Vândalos da Noite & Invasão & Turma da Barra \\
\hline Demônio de Rua & Ratos Destruidores & Sideral \\
\hline Terror do Barreiro & \multicolumn{1}{c|}{ JURUNAS } & \multicolumn{1}{c|}{ TAPANÃ } \\
\hline \multicolumn{1}{|c|}{ CREMAÇÃO } & Terroristas da Tupinambás & Desordem \\
\hline Arruaça & Fugitivos da Febem & Elite \\
\hline Malucos & Ratos da Paz & Habilidosos do Jet \\
\hline Pivetes da Ponte & Raticidas & Ratos Vilões \\
\hline Meninos Inocentes & Ratos Pirados & Turma do Vamp \\
\hline Meninos de Rua & Meninos Malvados & Monarquia \\
\hline Sindicato dos Selvagens & Os Selvas & ICOARACÍ \\
\hline TERRA FIRME & & Pivetes \\
\hline Invasores & Quik Silver & Bagunça \\
\hline Falange Vermelha & Tropa Homicida & Desordem \\
\hline Demolidores Dark & Galera do Agito & Galera da Sexta Rua \\
\hline Galera da Lauro Sodré & São Cristóvão & Errados para Sempre \\
\hline Demolidores do Futuro & Galera do Flash & Fúria \\
\hline Sindicato dos Perdidos & Ratos da Feira & \\
\hline PEDREIRA & Tarados e Malucos & \multicolumn{1}{c|}{ SACRAMENTA } \\
\hline \multicolumn{1}{|c|}{ Terrorismo } & Turma da Marcílio & Ratos do Barulho \\
\hline Falange & Demônios de Rua & Ratos do Porto \\
\hline Abandonados & Ratos da City & Ratos da Sacramenta \\
\hline Turma da União & Bebê Diabo & \\
\hline
\end{tabular}

Fonte: Informações coletadas em trabalho de campo (2014).

$\mathrm{Na}$ tabela acima, destacam-se as principais gangues de rua, galeras ou tribos urbanas como alguns preferiam chamar. Essas gangues estavam territorializadas em vários bairros da periferia de Belém e na região metropolitana. A década dos anos de 1990 foi considerada a década das gangues de rua, elas contribuíam para a proliferação da violência urbana, já que existiam conflitos entre elas. Neste artigo, preferiu-se não destacar 
todos os bairros de Belém, mas apenas aqueles que estão sob as relações dos territórios do narcotráfico. As gangues criavam alianças com outras galeras de ouros bairros, quanto mais gangues presentes neles, mais conflitos se manifestavam em função da disputa pela hegemonia sobre eles. Em Belém, ainda se tem a presença de pichadores que consideram suas pichações uma arte revolucionária ou uma arte de rua, algo que é subjetivo a eles. Os pichadores que desde os anos de 1990 continuam a pichar pela cidade são chamados de velha guardas $^{13}$.

Fotografia 1- Pichação no bairro do Benguí com o símbolo da gangue da Q.S

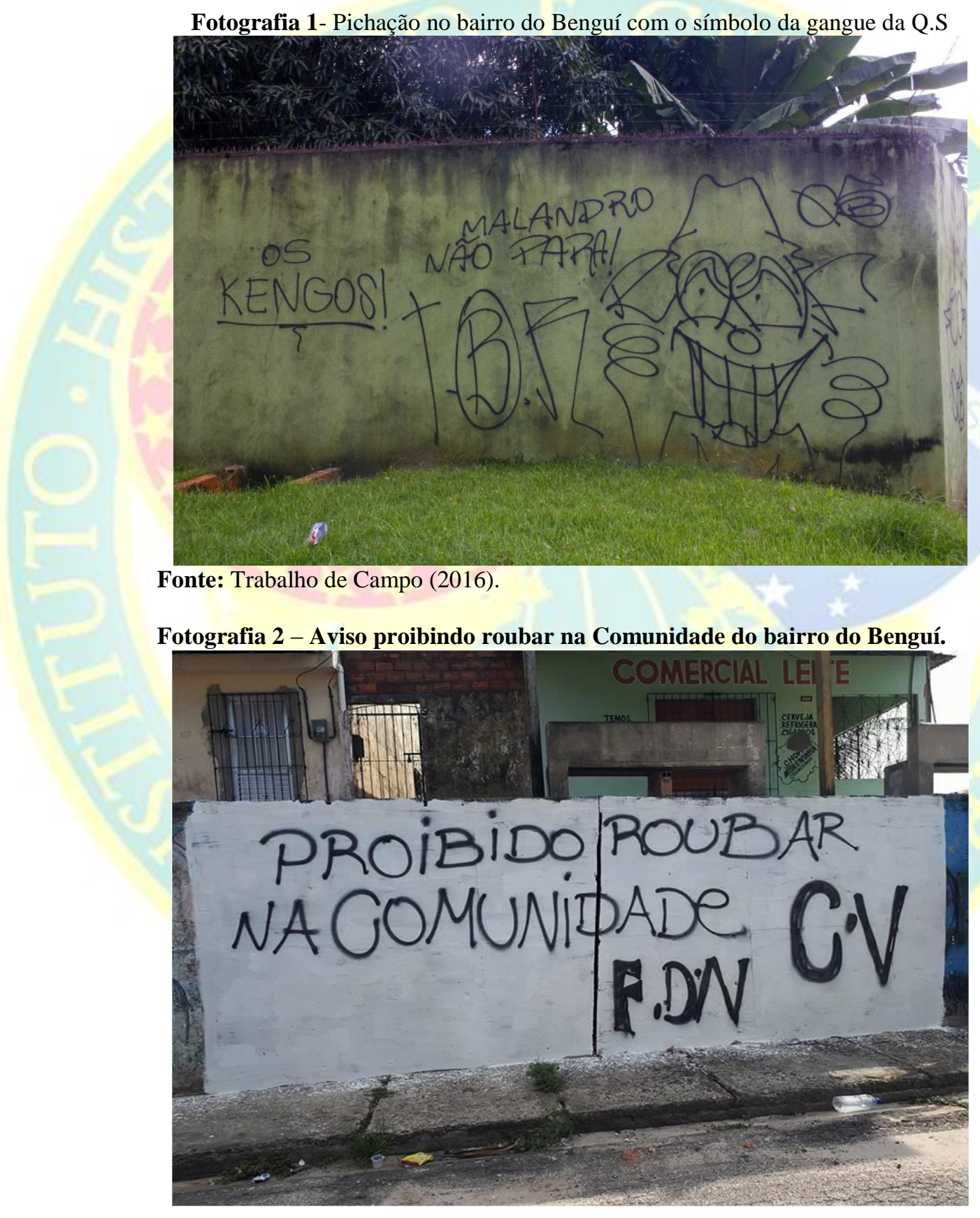

Fonte: Pesquisa de Campo (2016).

\footnotetext{
${ }^{13}$ O termo "velha guarda", no grupo dos pichadores, significa fazer referências aos pichadores mais antigos que ainda continuam em atividades.
}

Revista do Instituto Histórico e Geográfico do Pará (IHGP), (ISSN: 2359-0831 - on line), Belém, v. 07, n. 02, p. 119 141, jul.-dez. / 2020. 
A fotografia 1 acima foi registrada no bairro do Benguí na área de expansão de Belém. Ela traz o símbolo da Q.S que significa a gangue Quik Silver do bairro do Una o que expressa que há uma relação entre os dois bairros, pois na parede tem outra sigla que é da T.O.R do Benguí ${ }^{14}$ e os Kengos. Já a fotografia 2 destaca o aviso de orientação do Comando Vermelho de Belém proibindo assaltos na comunidade. Trata-se de uma estratégia para atrair os moradores para o seu círculo de influência e evitar ocorrências policiais relacionadas a pequenos furtos e roubos que atraem a polícia e comprometem o comercio/varejo da droga. Assim, os territórios do tráfico de drogas vão firmando-se e criando relações políticas nos bairros. Cada bairro é comandado por um grupo que tem o seu patrão. Os patrões do tráfico ${ }^{15}$ desenvolvem relações de apadrinhamento ou paternalistas com a população e dão os comandos que orientam ações do grupo sobre o território.

Os patrões do tráfico podem ou não morar na periferia, opinam por aquilo que lhes é mais conveniente no momento, ou seja, controlar de fora ou controlar de dentro esses bairros. Olheiros, aviãozinhos e soldados do tráfico se encarregam de obedecer aos comandos do patrão e impõem a lógica do controle, do disciplinamento e da regulação dos sujeitos. Essas práticas sociais organizam um espaço delimitado, identificados, controlados e territorializados. Por fim, são territórios na periferia que sofrem todos os tipos de violência; da exclusão à dominação. Recebem uma cultura de violência reproduzida pelo tráfico de drogas, pelas milícias e pelo Estado.

\section{DOS “AGLOMERADOS URBANOS DE EXCLUSÃO” ÀS “TERRITORIALIDADES PRECÁRIAS" NA PERIFERIA DE BELÉM}

Acredita-se na importância em se fazer um esforço teórico e empírico que possa enxergar nas formas precárias de produção do espaço urbano alguma relação direta ou indireta com a produção de micro relações de poder que se constituem e ajudam a organizar as redes do tráfico de drogas em Belém, considerando também todas as formas precárias de inserção da população que podem ou não ser aproveitadas pela economia do crime.

Nesse sentido, a leitura do espaço passou a ser fundamental para que se pudesse perceber os desdobramentos os quais levam a múltiplas formas de se pensar as ações da sociedade sobre ele, e isso nos remete a perspectivas de se considerar o espaço geográfico como uma categoria privilegiada para se entender o território e suas relações de poder. Foucault (1976, p. 22) vai nos dizer que "passamos de grande obsessão pela História, no século XIX, para uma época que "talvez seja a época do espaço". A emergência do espaço

\footnotetext{
${ }^{14}$ T.O.R quer dizer Torcida Organizada Remoçada do Benguí, que é uma torcida uniformizada do Clube do Remo. As torcidas de Remo e Paysandu também alimentam disputas territoriais.

${ }^{15}$ Patrões do tráfico são como os chefes do tráfico de drogas são chamados em Belém.
} 
com tamanha força dar-se-ia porque estaríamos vivendo agora a "época da simultaneidade", da "justaposição", "do perto e do distante, do lado a lado, do disperso"

Sendo assim, considerando que se vive hoje em uma sociedade em redes, fica fácil perceber tal relação com os espaços que passaram a compor a dinâmica das redes do narcotráfico em Belém, pois não podemos esquecer que a globalização permitiu também a expansão de variados tipos de conexões, e entre elas, as conexões perversas das redes ilegais do crime organizado.

Além disso tudo, a globalização promoveu uma "fragmentação" ou "inclusão precária" do espaço e da sociedade. Estaríamos assim diante daquilo que Castells (1997) definiu como "integração perversa", ou seja, atividades relacionadas à economia do crime, e teríamos como exemplo: o contrabando, a biopirataria, o tráfico de pessoas, o tráfico de drogas e a lavagem de dinheiro, dentre outros problemas.

Os bairros são espaços sociais construídos ao longo do tempo pelas atividades humanas com ou sem o incentivo do Estado. Então, foi dessa forma que se deu a configuração espacial de Belém: num primeiro momento confinada (a partir dos anos de 1950), com o surgimento dos bairros do Guamá, Cremação, Jurunas, Terra Firme e Barreiro; num segundo momento (a partir dos de 1980), a sua fase dispersa como o expansão dos bairros do Benguí, Cabanagem e Vila de Icoaraci.

Destaca-se aqui apenas os bairros que foram investigados durante a pesquisa que deu origem a este texto. Ressalta-se que a dispersão urbana também se deu em direção ao município de Ananindeua no sentido da rodovia BR-316 e rodovia do Coqueiro, contribuindo para a formação metropolitana de Belém. Vários bairros populares que surgem nesse momento são resultados de uma luta histórica da população por direito à moradia, são, portanto, sinônimos de resistências em meio aos processos de integração/exclusão dos projetos de modernização e produção capitalista do espaço.

Então, ao acompanharmos esse contexto, temos uma política urbana que tem um histórico de negligências relacionadas à infraestrutura urbana nas periferias. As estratégias e ações do Estado foram insuficientes no que diz respeito ao planejamento. Esse fato contribuiu para aprofundar ainda mais as condições adversas de sociabilidades. As contradições socioespaciais encontradas nas periferias tornaram-se então um dos vetores para a configuração geográfica dos territórios do tráfico de drogas.

As espacialidades urbanas operam de forma dinâmica na construção de identidades territoriais, estas que são associadas a diversas formas de reprodução social, entre as quais, a formação de redes sociais do crime. Pode-se dizer que o tráfico de drogas em Belém cria identidades territoriais urbanas que constroem relações de poder, trocas de informações e conflitos durante os processos de apropriação e dominação dos territórios. Ademais, deve ser interpretado como um tipo de fluxo que está no local, mas não nasce nele. Assim, cada bairro da periferia inserido nesse contexto é apenas uma parte do todo, que é a cartografia do poder e suas múltiplas escalas de ação construídas pelo crime organizado transnacional.

Reafirma-se a ideia de que a expansão periférica de Belém se deu por meio de processos desterritorializadores, nos quais parte da população expulsa das áreas centrais e a população que perde suas 


\section{Gangues, pichações e facções: \\ Evolução e configuração geográfica dos territórios do tráfico de drogas na periferia de Belém}

terras no campo e migra do interior do estado do Pará a capital vão encontrar nas áreas de baixadas e nas áreas distantes terrenos disponíveis para serem habitados por meio de processos organizados de ocupação. É assim que a periferia surge como espaços de resistências e condições de existências diante de uma urbanização que nega a cidadania e promove a exclusão social ou inclusão precária como prefere Martins (1997).

Posto isso, referindo-se ao conceito de exclusão em seu sentido mais estritamente social, alguns autores como o sociólogo José de Souza Martins (1997) têm preferência em utilizar o termo inclusão precária ao invés de exclusão social. O autor propõe uma análise da leitura sociológica-política, e não economicista, como afirma Martins:

[...] rigorosamente falando, não existe exclusão: existe contradição, existem vítimas de processos sociais, políticos e econômicos excludentes; existe o conflito pelo qual a vítima dos processos excludentes proclama seu inconformismo, seu mal-estar, sua revolta, suas esperanças, sua força reivindicativa e sua reivindicação corrosiva. Essas reações [...] constituem o imponderável de tais sistemas, fazem parte deles ainda que os negando (MARTINS, 1997, P. 14).

Nesse sentido, de acordo com a ideia de Martins (1997), não existe exclusão social, o que existe é uma contradição causada pelos processos sociais, políticos e econômicos que terminam por gerar certa exclusão, pois esses processos estão de acordo com a lógica do sistema, ou seja, representam as elites que estão no poder. Porém, de certa forma, a população pobre tem uma participação nesse sistema, mesmo que seja uma participação precária não significando uma total exclusão.

O tema da exclusão é mais um tema que faz parte de um conjunto (quase que se pode dizer "sistêmico") de categorizações imprecisas hoje em dia utilizadas para definir os aspectos mais problemáticos da sociedade contemporânea no terceiro mundo. Do tema da exclusão passou-se ao substantivo excluído, pressupondo, portanto, que se trata de uma categoria social e de uma qualidade sociologicamente identificável nas pessoas e nas relações sociais. Um atributo, como o atributo de trabalhador assalariado, aquele que, ao trabalhar, produz relações sociais singulares, gera contradições socialmente fundantes e engendra um tipo de mentalidade historicamente essencial. Algo, portanto, que corresponderia a uma certa consciência social das próprias vítimas da exclusão. No entanto, não é verificável na prática e na vivência dos chamados "excluídos" (MARTINS, 2002).

De fato, um dos dilemas é que uma nova dicotomia surge: os incluídos em oposição aos excluídos. Essa construção, entretanto, nega o ponto de vista praticamente hegemônico nas Ciências Sociais que é justamente a perspectiva antidualista de inspiração marxista: é um disparate nos referirmos aos "excluídos" quando esses mesmos indivíduos não se encontram fora, mas, antes, inseridos, embora precariamente, no sistema econômico. "Qual o sentido de falar em duas ordens de realidade, dos "incluídos" e dos "excluídos", se ambas são produzidas por um mesmo processo econômico que, de um lado, produz riqueza e, de outro, miséria?" MARTINS, 1997, p. 53). 


\section{Gangues, pichações e facções: \\ Evolução e configuração geográfica dos territórios do tráfico de drogas na periferia de Belém}

Inclusive, nas condições brasileiras, esse "lupemproletariado" gerado pelo capitalismo, além de funcional ao sistema enquanto exército de reserva, é utilizado pelos segmentos integrados ao mercado de consumo como mão de obra, realocando cada vez mais recursos para o setor dinâmico (1997 p. 53). Não podemos nos esquecer das classes médias que, no geral, não hesitam em contratar empregados domésticos pagando baixos salários para tomar conta de suas casas, de sua comida e de sua sujeira, ao mesmo tempo em que não suportam que estes mesmos empregados utilizem os seus banheiros e o seu elevador.

$\mathrm{Na}$ verdade, a categoria exclusão é resultado de uma metamorfose nos conceitos que procuram explicar a ordenação social que resultou do desenvolvimento capitalista. Mais do que uma definição precisa de problemas, ela expressa uma incerteza e uma grande insegurança teórica na compreensão dos problemas sociais da sociedade contemporânea (MARTINS, 2002).

Sendo assim, devemos nos livrar de estereótipos que nos enganam e que ao invés de expressar uma prática - a exclusão - acabam por induzi-la e, mais ainda, faz-se necessário modernizarmos a sociedade, revolucionando suas relações arcaicas, ajustando-as de acordo com as necessidades da sociedade como um todo e não de acordo com os interesses do modo de produção capitalista. Em Belém podemos, visualizar várias formas de "inclusão precária" que vão desde as práticas mais emblemáticas das relações de trabalho até o tipo de organização socioespacial que é configurado como estratégia de (sobre)vivência da população pobre em aglomerados.

Haesbaert (2004), Escolhe a expressão “aglomerados de exclusão" para traduzir a dimensão geográfica ou espacial dos processos mais extremos de exclusão social porque ela parece expressar bem a condição de "desterritorialização" - ou de "territorialização precária" - a que estamos nos referindo, a começar pelos próprios significados que carrega no senso comum explicitados pelo Novo Dicionário Aurélio da Língua Portuguesa, tais como; aglomeração, ajuntamento, agrupamento, amontoamento, dentre outros significados. Segundo este autor,

O termo "aglomerado" serve tanto para definir "conjuntos, agrupamentos" em geral - de onde provém concepções como as de "aglomeração humana" ou "urbana", quanto para significar "amontoamento", um tipo de agrupamento em que os elementos estão "ajuntados confusamente". Esta é, aproximadamente, a noção aqui proposta para aglomerados de exclusão, espécie de "amontoados" humanos, instáveis, inseguros e geralmente imprevisíveis na sua dinâmica de exclusão" (HAESBAERT, 1997, p. 148).

Sendo assim, podemos nos referir à problemática da habitação no Brasil, sobretudo, em suas metrópoles, nas quais o problema da habitação está no centro das nossas questões urbanas, em razão da exclusão de grande parte da população no mercado imobiliário formal. A "solução" para esse déficit habitacional tem sido a inclusão marginal na cidade, prevalecendo uma lógica perversa que é produtora da maior parte dos nossos problemas. Na Amazônia, a expansão urbana de Belém foi caracterizada pelo permanente e crescente descompasso entre o lento crescimento urbano e a rápida expansão de suas margens. 
Nos anos 1980 e 1990, Belém tornou-se conhecida como a "capital das invasões"16 devido aos vários movimentos de ocupação da terra para a moradia que explodiram em direção à área da Augusto Montenegro no sentido Icoaraci e também no sentido do município de Ananindeua, além de ter que lidar com as invasões em sua zona periférica do centro. Nesse processo, surgiram as áreas da Cabanagem, Paracurí I e II, Tucunduba I e II, Invasão da Malvina, Invasão do Catalina, dentre várias outras que não cabem descrever aqui.

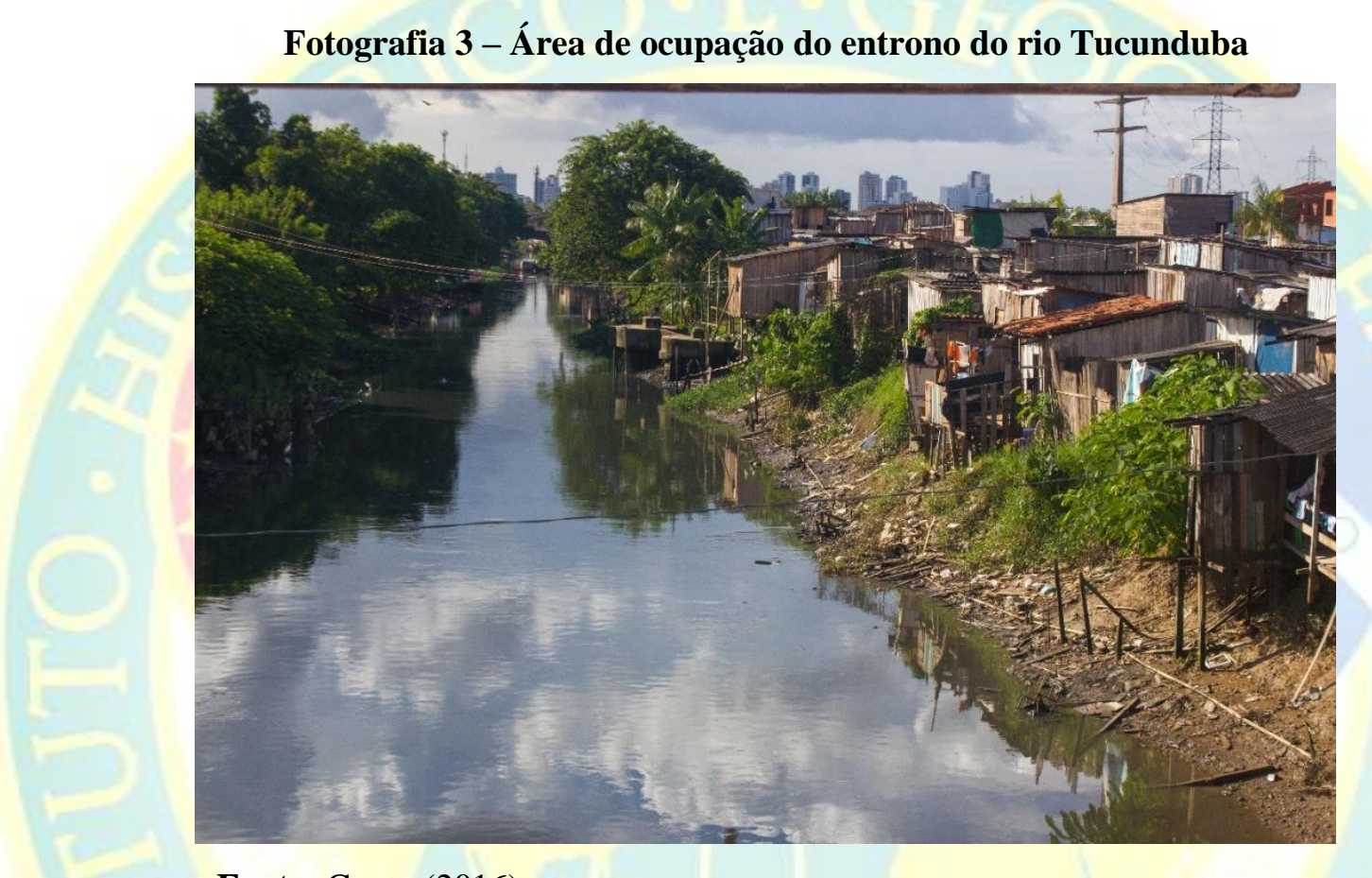

A fotografia 3 é um exemplo de "aglomerado de exclusão", instável, inseguro e precário, resultado de um processo de urbanização no qual o planejamento institui uma forma biopolítica de se pensar o espaço, e, portanto, define geograficamente e politicamente quem vive e quem morre. Essa definição cria a narrativa de que nas periferias há uma reprodução populacional de uma massa considerada perigosa e por isso "matável". Sem cidadania, essa população se torna uma espécie de mortos vivos, tem seus direitos negados e passa a sofrer todas as formas de reprodução de discriminação e de violência. Em relação à questão da habitação popular, pode-se definir esses espaços como aglomerados urbanos de exclusão, ou seja, áreas de intensa ocupação com a presença de habitações construídas espontaneamente sobre áreas de risco, enfrentando problemas de rede de esgoto, tratamento de água potável, saneamento básico, distribuição de energia elétrica, além disso, enfrentam problemas de saúde pública.

Foucault (2002[1976]) se refere à população como "um novo corpo: corpo múltiplo, corpo com inúmeras cabeças, se não infinito pelo menos necessariamente numerável” (p. 292), e nesse sentido, passará a

\footnotetext{
${ }^{16} \mathrm{Na}$ época, era como popularmente e pejorativamente chamavam as áreas habitadas resultantes de movimentos de ocupação espontânea.
} 
ser objeto de biopolítica, “a população como problema político, como problema a um só tempo cientifico e político, como problemas biológicos e como problemas de poder (FOUCAULT, 2002, p. 293), "que irá se sobrepor à sociedade disciplinar mais preocupada com o controle individual" (HAESBAERT, 2004, p. 325).

Esta situação de instabilidade, constante movimento e condições de sobrevivência extremamente precárias revelam se não um "aglomerado de exclusão", no sentido aqui aludido, pelo menos um processo em direção a ele. Na verdade, a população excluída dos "aglomerados" pode não ser socialmente relevante - pelo menos momentaneamente - nem na condição de trabalhadores (diante do desemprego estrutural), nem de consumidor (dado seu nível extremo de pobreza, muitas vezes sobrevivendo, apenas com os restos deixados pela "sociedade do consumo"[...]. Não se trata nunca de uma exclusão total, existindo laços que os ligam à sociedade formalmente instituída que as produz. Considerada esta restrição, não é exagero afirmar que muitas vezes eles constituem "uma massa indefinida e desintegrada", como dizia Marx, sem uma clara função social. (HAESBAERT, 1996, p. 324).

Os aglomerados que estão aqui sendo apresentados tratam-se de processos de ocupações espontâneas que caracterizam a expansão da periferia de Belém. Segundo dados do Instituto Brasileiro de Geografia e Estatística IBGE (2010), a Região Metropolitana de Belém (RMB) concentra $89 \%$ da população em aglomerado subnormais no estado do Pará. Se formos partir da análise em função do número de habitantes, são 1.131 .268 pessoas nessas condições, correspondendo a $52 \%$ de toda a população da RMB que é de 2.097.287. Entre todas as Regiões Metropolitanas do Brasil, Belém tem a maior proporção de residentes em favelas.

O IBGE classifica como aglomerado subnormal:

Um conjunto constituído de, no mínimo, 51 unidades habitacionais (barracos, casas etc.) carentes, em sua maioria de serviços públicos essenciais, ocupando ou tendo ocupado, até período recente, terreno de propriedade alheia (pública ou particular) e estando dispostas, em geral, de forma desordenada e densa. A identificação dos aglomerados subnormais deve ser feita com base nos seguintes critérios: a) Ocupação ilegal da terra, ou seja, construção em terrenos de propriedade alheia (pública ou particular) no momento atual ou em período recente (obtenção do título de propriedade do terreno há 10 anos ou menos); e b) Possuírem pelo menos uma das seguintes características: urbanização fora dos padrões vigentes refletida por vias de circulação estreitas e de alinhamento irregular, lotes de tamanhos e formas desiguais e construções não regularizadas por órgãos públicos; ou precariedade de serviços públicos essenciais (IBGE, 2010, p. 19).

Ainda segundo o IBGE (2010), na RMB estão as 12 maiores favelas do Brasil, uma delas é a baixada da Estrada Nova, que vai do Jurunas até o bairro do Guamá e aparece como a mais populosa de Belém com uma população de 53.129 moradores.

Podemos dizer que os "aglomerados de exclusão" são espaços de funcionamento de toda e qualquer forma de sobrevivência, o que facilita a inclusão precária de sua população em atividades informais inseridas na economia urbana que favorece também a uma territorialidade precária de sua população. Assim,

Os aglomerados de exclusão, mais do que espaços à parte, claramente inidentificáveis, são frutos de uma condição social, extremamente precarizada, onde a construção de territórios "sob controle" (termo redundante) ou "autônomos" se torna muito difícil, ou completamente subordinada a interesses alheios à população que ali se reproduz. A aparente desordem que 
rege esta condição, num sentido negativo de desordem, é fruto da não - identificação dos grupos com seu ambiente e o não - controle do espaço pelos seus principais "usuários". De qualquer forma, é como se o "vazio de sentido" contemporâneo, reproduzido na abordagem sociológica pela controvertida noção de "massa" tivesse sua contrapartida geográfica na noção de "aglomerados de exclusão" (HAESBAERT, 1996 p.327).

O narcotráfico atribui, assim, uma importante função política para os "aglomerados de exclusão". Ele se institui, cria redes, seleciona pessoas e envolve esses espaços em múltiplas relações que constroem os processos de territorialização. Os aglomerados, então, socialmente instituem ações de dentro para fora, mas sob a influência e vigilância do tráfico, são controlados de fora para dentro. Foi, nesse contexto, que os territórios do tráfico de drogas foram instalados na ocupação do Buraco Fundo, na Invasão do Tocantins e na rua Uxiteua em Icoaraci, no Tucunduba na área do Guamá e da Terra Firme, na Cabanagem, na "área de invasão" do Barreiro, no Jurunas, Benguí e Sacramenta. Todos esses bairros apresentam internamente aquilo que pode ser identificado como "aglomerados de exclusão" ou aglomerados urbanos de exclusão. Com efeitos sobre os territórios, a inserção de jovens da periferia nas redes do tráfico de drogas não corresponde apenas a um tipo de integração perversa, mas também é uma forma de inclusão precária.

As estratégias de lutas da população por direito à moradia construíram formas precárias de territorialização ou territorialidades precárias. E o tráfico de drogas, inteligentemente, se apropriou de algumas dessas áreas, tendo controle inclusive de algumas lideranças comunitárias, sobretudo, pela lógica da coerção e propagação do medo. As redes territoriais postas sobre o espaço de Belém possibilitaram uma organização política e econômica que produz territórios em zonas importantes da periferia de Belém. Logo, os processos históricos de desterritorialização da população, relacionados à exclusão social" ou "exclusão socioespacial", envolvem, portanto, esses aglomerados que aqui foram identificados como aglomerados urbanos de exclusão. Sendo assim, por mais que seja sinônimo de precarização a reterritorialização faz parte da natureza do homem que busca o seu território, assim se dá a "territorialidade precária" e suas várias variáveis de interpretação e de definição do que é precário.

No espaço urbano de uma metrópole como Belém que apresenta uma periferia dispersa, reconhece-se a grande diversidade socioespacial que se manifesta, sobretudo, nesses "aglomerados urbanos de exclusão", sobretudo, quando a referência são os processos de expansão urbana associados à precariedade na produção do espaço, à fragmentação do tecido urbano, à instabilidade social, à insegurança e à violência urbana. Sem políticas públicas eficientes e sem uma política urbana adequada, esses espaços tornam-se fundamentais à produção de uma margem que se permite envolver pela criminalidade e pela precariedade das relações de trabalho. Nos bairros populares e nas favelas, a presença da violência urbana não produz apenas efeitos desorganizadores, mas ela pode também produzir efeitos organizadores como faz o tráfico de drogas. 


\section{ORGANIZAÇÃO DO NARCOTRÁFICO NO ESPAÇO URBANO DE BELÉM: DOS TERRITÓRIOS EM REDES AOS TERRITÓRIOS EM ZONA}

O tráfico de drogas em Belém se dá por duas formas de organização espacial, uma que parte de uma lógica reticular, que coloca Belém como uma espécie de "nexo" ou "nó" de uma rede muito mais ampla de organização espacial do tráfico, assim como os bairros internamente também compõem essa estrutura e, portanto, não são espaços isolados de um contexto regional-global. A segunda forma trata diretamente dos bairros em si e suas organizações intraurbanas, ou seja, uma lógica mais zonal de organização, entre redes e zonas, temos então o território-rede e o território-zona.

Quando se trata de Belém, temos que considerar que as redes do tráfico de drogas só se definem a

partir das micro relações de poder que são estabelecidas nos bairros, onde estas micro relações que conseguem compor um conjunto de relações que definem a configuração de territórios sobre o controle do tráfico de drogas que, ao se articular em redes, ganham uma dimensão mais ampla.

Então, deve-se deixar evidente que, no caso da metrópole amazônica, foram justamente estas micro relações que foram instituídas e que deram condições para que hoje toda a estrutura do tráfico de drogas fosse predominantemente em redes. Não que estas formas mais tradicionais de territórios desaparecessem, mas as redes organizaram um movimento de distribuição e controle desses bairros de tal forma que eles são fortemente influenciados por ordens "externas".

Essas relações entre o "dentro" e o "fora" que são intermediadas pelas redes, redes ilegais que se estabeleceram sobre a região amazônica, é que ajudam a enxergar essa conexão territorializada, e, portanto, Belém convive em meio os territórios-rede ou território em redes, e territórios-zona. Diante desse contexto, tem-se uma multiterritorialidade, a qual segundo Haesbaert (2002) estará reunida em três elementos essenciais que são; os territórios-zona, os territórios-rede e os "aglomerados de exclusão".

Nos território-zona, prevalece a lógica política; nos territórios-rede, prevalece a lógica econômica e nos aglomerados de exclusão ocorre uma lógica socioeconômica das pessoas. Haesbaert (2002) destaca que esses três elementos não são mutuamente excludentes, mas integrados num mesmo conjunto de relações socioespaciais, ou seja, compõem efetivamente uma territorialidade ou uma espacialidade complexa, somente apreendida através da justaposição dessas três noções ou da construção de conceitos "híbridos", como o território-rede.

Sendo assim, o narcotráfico atua na periferia da cidade de duas formas: uma a partir da configuração de um território-rede, organizado de "fora para dentro"; e outra por meio da construção de um território-zona, ou seja, organizado de "dentro para fora". Os dois conceitos assim não se anulam, são complementares e interdependentes. Para a manutenção do território-zona, é preciso uma articulação em rede que abasteça os pontos de venda de droga, e nesse sentido a zona está dentro de uma lógica reticular que dá sentido ao territóriorede, sobreposto sobre o território-zona. 
Pensando nas formas de distribuição da cocaína, em especial para a cidade de Belém, tem-se que imaginar as mais "inteligentes" formas de transportes da droga, assim como, também se deve considerar a importância que a cidade adquire pelo fato de estar banhada por uma baia (baía do Guajará) que permite ter um contato com o rio a partir do desenvolvimento de um comércio regional que apresenta um intenso fluxo de pessoas e de mercadorias. Em meio a essa característica, traficantes "camuflam" a droga, a qual vem transportada por barcos, onde ribeirinhos são aliciados e muitas vezes os donos das embarcações nem sabem que carregam droga, que pode vir camuflada inclusive dentro de frutas, pescados, dentre outras mercadorias. Uma tarefa bastante difícil para a segurança pública.

Por isso, pontos e trapiches tornaram-se portas de entradas de cocaína em Belém. Além disso, somando-se às estradas, o narcotráfico organiza a sua estrutura em redes que envolve toda a metrópole, por isso é tão difícil conter esse tipo de organização em Belém, depois dos territórios definidos nos bairros, tornase fácil abastecer e controlar de "fora" o comércio. O mapa 01, baseado em relatório de campo e registros de apreensão da Polícia, mostra uma cartografia das redes de distribuição em Belém.

Mapa 1 - rede intraurbana de distribuição de drogas no espaço de Belém

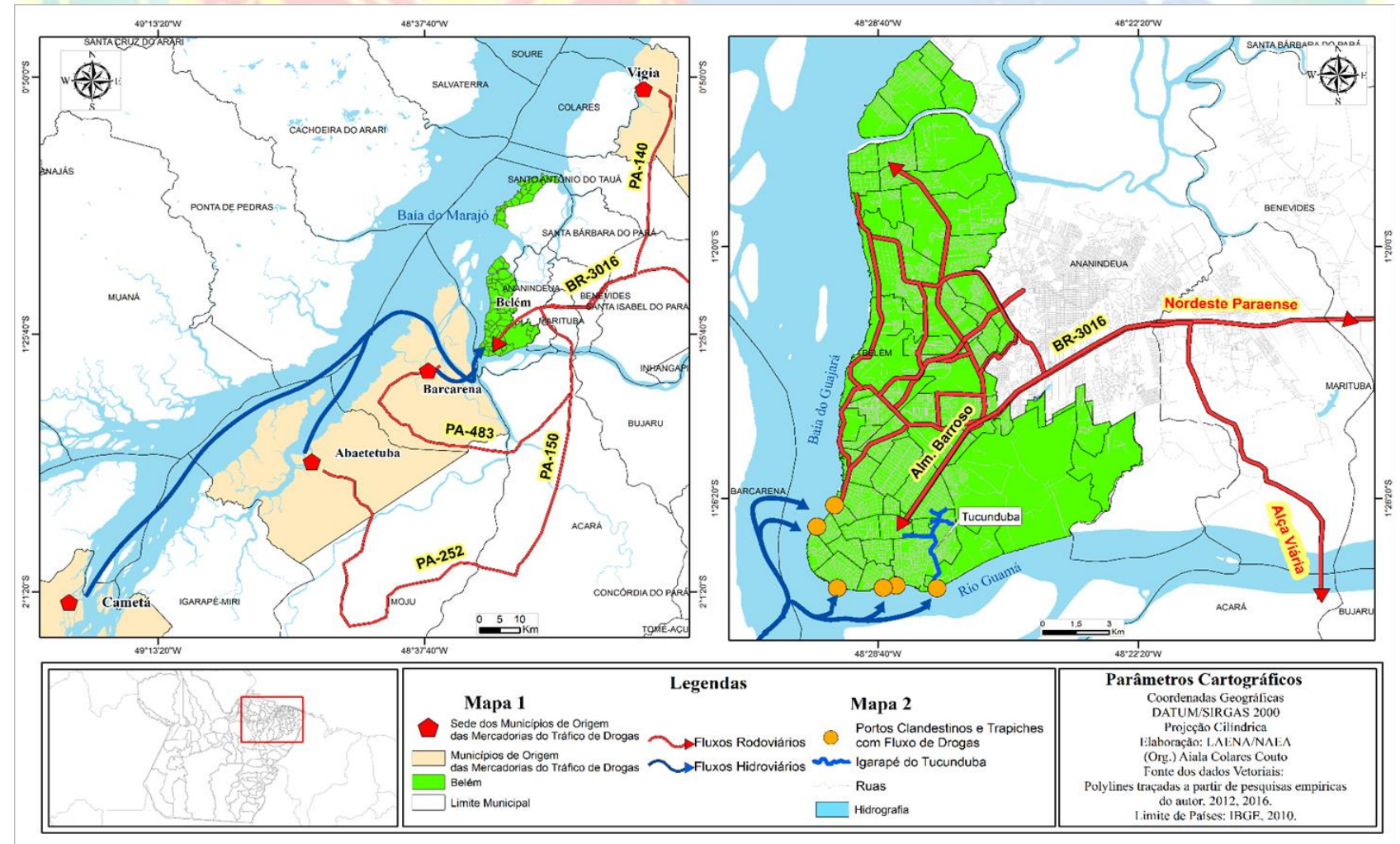

Fonte: Pesquisa de Campo (2016)

É fácil de identificar os pontos mais concentrados na Zona Sul de Belém onde estão os bairros da Cremação, Guamá e Terra Firme, com destaque para o Igarapé do Tucunduba onde ao entorno de seu leito - que foi 
ocupado por um forte processo de ocupação espontânea - temos empiricamente o limite entre os dois bairros; e o bairro do Jurunas que teve seu processo de ocupação também associado ao crescimento espontâneo. Porém, os bairros nascem na beira do rio e ambos mantem formas precárias de habitação no entorno do rio, como trapiches, portos, estancias, comércios e um fluxo continuo de pessoas e mercadorias que fazem parte da interação com as ilhas de Belém. É nesse movimento que o narcotráfico se territorializa hoje, controla os fluxos de cocaína que são distribuídas na cidade, impulsionam um comércio interno, mas ao mesmo tempo dependente de uma ação externa. De uma forma ou de outra, a rede é o elemento que define as formas de controle externo.

Se buscar a relação de Belém com as redes do tráfico de drogas, remete-se ao papel da Amazônia como área de trânsito da cocaína para mercados nacionais-mundiais, e claro, destaca-se que o consumo de cocaína nos últimos anos tem aumentado, o que, de certa forma, destaca o país como segundo principal mercado consumidor de cocaína, ficando atrás apenas dos EUA de acordo com o relatório do Escritório da Nações Unidas Sobre Crimes Globais de 2014.

Esse processo de territorialização do tráfico de drogas utiliza-se de fluxos materiais (tráfico de drogas e armas e contrabando de mercadorias) e imateriais (fluxos de capitais para lavagem de dinheiro e fluxos de informações) que acompanham a evolução dos mercados e utilizam-se também de vantagens da revolução tecnológica para aprofundar suas transações comerciais. Com maior fluidez no espaço, as fronteiras tornamse porosas e, no caso da Amazônia, ainda temos o problema da dimensão geográfica que por muito facilita o clima de tensão constante em suas fronteiras precariamente vigiadas.

O destino torna-se as cidades da região, principalmente as metrópoles como Belém e nesse jogo o território ganha uma dimensão importante para o controle dos fluxos que alimentam os bairros de Belém no contexto do narcotráfico. Por isso, Haesbaert (2004) vai deixar claro que não se trata simplesmente de priorizar o expressivo sobre o funcional, mas de reconhecer sua permanente imbricação. Se o território hoje, mais do que nunca, é também movimento qualquer, ou de um movimento de feições meramente funcionais, ele é também um movimento dotado de significado, de expressividade, isto é, que tem um significado para quem o constrói e/ou para quem dele usufrui. O tráfico tem essa característica em Belém.

As pichações, os bondes, os significados que são construídos representam um valor simbólico para os seus sujeitos, pois - uma vez reconhecidos - podem significar respeito e obediência, mas por outro lado, também podem representar tensões e conflitos pelo uso do território ou domínio do espaço. Constantemente, em Belém nos bairros do Guamá, Jurunas e Terra Firme, ocorrem ou se manifestam conflitos de toda ordem relacionados com o tráfico de drogas e seus sujeitos, o que não é diferente também no Benguí, Cabanagem, Sacramenta, Barreiro e Icoaraci. Hoje a expressividade do narcotráfico na metrópole é indissociável à relação entre redes e territórios. Belém sob essa influência dos fluxos, ao se tornar ponto da rede em escala regionalglobal e apresentar zonas em uma escala intraurbana metropolitana, vai cumprindo esse duplo papel na economia perversa do crime. Torna-se, também, palco de lavagem de dinheiro com diversas formas de 
Evolução e configuração geográfica dos territórios do tráfico de drogas na periferia de Belém incorporação do dinheiro sujo do tráfico aos mercados urbanos, sobretudo nos próprios bairros sobre o seu controle.

Mapa 2 - Organização espacial do Narcotráfico em Belém

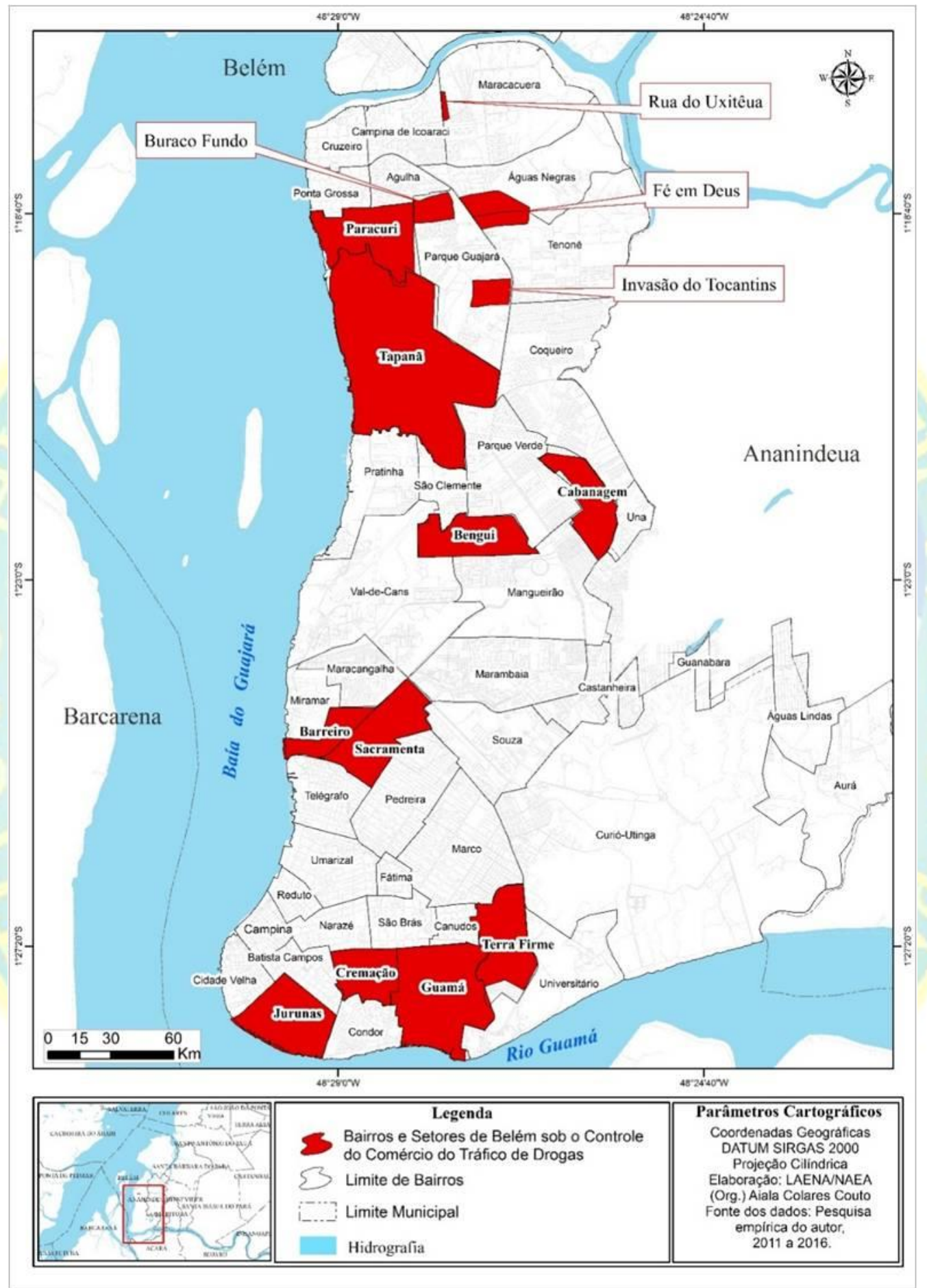

Fonte: Trabalho de Campo (2016).

O mapa 02 acima nos apresenta uma cartografia dos bairros ou setores - como preferimos definir para algumas áreas que estão sobre o controle do narcotráfico. Da Zona Sul até a Zona Norte, bairros inteiros 
transformaram-se em territórios-zonas conectados a territórios-redes, onde a rede acaba por dar sentido nessa relação na qual o exercício do poder é fundamental para que ela se efetive. É a partir desses bairros que Belém se insere na dinâmica do tráfico, por eles, se organiza toda a atividade e movimento que dão sentido ao comércio/varejo de cocaína, principalmente.

Assim, os bairros são "portas de entrada" da droga pelos rios, onde atividades legais se misturam às atividades ilícitas, como nos mais localizados na Zona Sul (o que foi destacado antes), área da cidade em que diversas atividades econômicas ocorrem na beira dos rios e que mantem esse fluxo cotidiano em que o rio é um elemento importante para se pensar as redes. Entretanto, além disso tudo, não se pode restringir o debate apenas a essa análise que veicula o tráfico de drogas em uma relação muito mais tradicional e do tempo lento que envolve a Amazônia. Existem formas mais modernas de conexão que se destacam pelas redes técnicas mais modernas e estão em uma escala de poder mais ampla do que se imagina, conexões que, de certa forma, promovem a territorialização do narcotráfico de um lado; por outro, promovem a desterritorialização do Estado.

Seria exagero afirmar que o Estado perdeu total controle sobre o seu território, só que aqui se fala de uma atividade que está inserida em uma "economia subterrânea", muitas vezes invisível aos olhos do Estado, e quando visualizada, incorporada por eles em esquema de corrupção e, nesse caso, o tráfico confunde-se com a própria instituição Estado.

$\mathrm{Na}$ Zona Sul de Belém, mais precisamente nas áreas de baixadas que obedecem ao caráter inicial da formação da metrópole confinada, temos os bairros da Condor, Cremação, Guamá e Terra Firme, destacando a relação que esses bairros estabelecem com o rio, com os portos, com as rotas do tráfico de droga em uma escala intraurbana. É a parte da cidade onde os portos ou trapiches desempenham o papel de receptores. Sendo assim, em meio a uma mistura com as diversas mercadorias que historicamente fazem parte do cotidiano destes bairros, o tráfico consegue encontrar um local privilegiado para camuflar suas mercadorias.

Na Zona Oeste de Belém, ainda dentro da formação confinada da metrópole, destacam-se os bairros do Barreiro, Pedreira e Sacramente, onde na região do Barreiro há um destaque maior, pois apresenta uma complexa organização espacial, na qual as áreas de difícil ou entorno do canal destacam-se pela presença de criminosos que praticam assaltos na área da avenida Pedro Alvares Cabral. Nesse sentido, destacam-se: o Canal da São Joaquim que liga os bairros do Barreiro, Sacramenta e Telégrafo, a passagem São Benedito e a Passagem Santa Rosa, nos bairros da Sacramenta e Pedreira; também há pontos dispersos em áreas de canais ou áreas que caracterizam ocupações espontâneas. O controle do tráfico sobre esses bairros está só na distribuição da droga, e os comados internos realizam suas atividades e prestam contas com o fornecedor. Assim, não há evidências de grandes traficantes ou chefões do tráfico residindo nesses bairros e tomando conta deles.

Na Zona Leste, os bairros do Benguí e Cabanagem se apresentam enquanto zonas territoriais do tráfico de drogas, com um destaque muito maior para o bairro da Cabanagem e sua conexão com o bairro do Uma. $\mathrm{O}$ 
crescimento desses bairros obedece a dispersão populacional para além da Primeira égua Patrimonial da cidade, é a fase de formação da metrópole dispersa, com expansão em direção à Avenida Augusto Montenegro no sentido Icoaraci e Outeiro.

Finalmente, a Zona Norte de Belém, na Vila de Icoaraci, o bairro do Paracurí, o Buraco Fundo, a Invasão do Tocantins, a passagem Fé em Deus e a Rua Uxiteua, fecham o nosso mapeamento de apresentação das áreas que estão sobre o controle do tráfico. Ressaltamos que, no caso da Zona Norte, não podemos também deixar de considerar a importância dos rios para a articulação do tráfico de drogas, bem como o processo de ocupação espontânea que também favoreceu a criação de uma organização complexa com becos e ruelas que facilitam a ação de pequenos aviãozinhos ou traficantes.

Os bairros seriam, assim, do ponto de vista das relações e de sua essência, os territórios fechados do tráfico de drogas, diante de uma articulação local e global, são nexos orientados pelos fluxos que perpassam os limites do Estado territorial, superpostos e dinâmicos nas formas de apropriação/dominação do espaço, complexos em sua composição e contraditórios em sua produção. Entretanto, quando se trata do narcotráfico, prevalece em sua natureza o exercício do poder, aquilo que dá sentido real para o território.

"Um território, antes de ser uma fronteira, é primeiro um conjunto de lugares hierarquizados, conectados a uma rede de itinerários. A territorialização engloba, ao mesmo tempo, aquilo que é fixação [enraizamento] e aquilo que é mobilidade; em outras palavras: tanto os itinerários quanto os lugares" (BONNEMAISON, 1981, p. 253-254 apud HAESBAERTH, 2004, p. 280). O território na perspectiva do narcotráfico está estruturado, zonal e reticular, de micro relações de poder até as relações mais macros, o poder está por toda a parte, essencial e necessário para a manutenção de uma atividade que desenha a sua própria Geografia, que rivaliza ou até compactua com outras estruturas territoriais.

As estruturas territoriais nos mostram que o território não é unidade homogênea, pois existe toda uma complexidade dos elementos que promovem as diversas configurações, algumas específicas de acordo com a perspectiva estruturante do território, por isso, Para Deleuze e Guattari (1997, p.120-121), o território "tem uma zona interior de domicílio ou de abrigo, uma zona exterior de domicílio, limites ou membranas mais ou menos retráteis, zonas intermediárias ou até neutralizadas, e reservas ou anexos de energia".

Para Haesbaert (2004, p. 282):

Nesta abordagem, fica mais fácil visualizar um território forjado numa lógica zonal ou em superfície, como uma área delimitada por fronteiras. Ela sugere também um território no sentido mais tradicional ao estabelecer uma espécie de hierarquia entre interior-exterior, "residência", "zonas intermediárias" e "anexos". Deleuze e Guattari certamente não estão inspirados aqui num território de feições mais rizomáticas que, provavelmente, na sua interpretação, estariam mais associados a processos desterritorializadores.

O tráfico de drogas necessita de uma área de controle para o comércio/varejo da droga e, sendo assim, alguns grupos impõem limites e regras de acordo com seus códigos às pessoas de "fora" e de "dentro", 
sobretudo, aos sujeitos do tráfico que estão sob o controle efetivo dessa atividade. É, dessa forma, que se configura um território-zona ligado ao narcotráfico. É preciso chamar a atenção para fato de que o territóriozona só se define como tal pela predominância das dinâmicas "zonais" sobre as "reticulares", mas não pela sua dissociação. Ou seja, território-zona não estabelece em momento algum uma relação dicotômica ou dual com sua contrapartida, o território-rede (HAESBAERT, 2004, p. 286).

Para Haesbaert (2004), tem-se então duas formas ou lógicas de territorialização: uma pela lógica zonal, de controle de áreas e limites ou fronteiras, outra pela lógica reticular, de controle de fluxos e polos de conexão ou redes. Para o autor, a diferença entre zonas e redes tem origem em duas concepções e práticas distintas do espaço, uma que privilegia a homogeneidade e a exclusividade, outra que evidencia a heterogeneidade e a multiplicidade, inclusive no sentido de admitir as sobreposições espaço-temporais.

Com grande impacto sobre as metrópoles, o narcotráfico promove a criação de territórios urbanos desterritorializados em relação às normas legais não reconhecidas e em relação também à própria figura do Estado, e não podemos esquecer que o Estado - enquanto instituição jurídico-política - também tenta de todas as formas regular o uso do território, impondo uma lógica de violência legítima que culmina nas políticas de combate ao narcotráfico que muitas vezes se confunde com formas biopolíticas de controle do espaço e, nesse sentido, é importante reconhecer as tentativas de reterritorialização do Estado ou novas formas de territorialização.

Sobre as redes, é imprescindível uma análise que dê conta de entende-las a partir da superposição de territórios que elas causam, pois se misturam com outras formas de territorialização, competem ou em alguns casos, aliam-se. O narcotráfico e o Estado atuam das duas formas, tanto territórios em redes quanto territórios em zonas, são criações de ambos, por isso é tão importante enxergar esta multiterritorialidade presente no espaço geográfico.

Então, ao tratar do narcotráfico em Belém, estaríamos diante de uma força que se enraíza no território, ou seja, um poder, que não arriscamos chamar de "poder paralelo", visto que existe uma relação imaterial, invisível ou virtual com as instituições ou com o próprio Estado, como visualizada em nossa análise. Por fim, a mais importante perspectiva diante do conceito de território para entender o narcotráfico na metrópole é a sua natureza puramente política que nos faz superar a definição de seus conceitos a partir da perspectiva de um poder "único", "legitimo" e "exclusivo" do Estado. São diferentes configurações territoriais, contínuas e descontínuas, zonais e reticulares ou superpostas, que dão sentido para a noção de multiterritorialidade.

\section{CONSIDERAÇÕES FINAIS}

Como visto, os territórios do narcotráfico em Belém passam por um processo de evolução que vai das gangues de ruas às facções que construíram as relações políticas instituídas de poder sobres as periferias da cidade. Isso resulta, então, em configurações geográficas que se sobrepõem aos territórios das gangues de pichadores que existiram nos anos de 1990. 
Além disso, o próprio processo de expansão urbana de Belém consolida a formação socioespacial de bairros populares nas áreas de baixadas e na periferia mais distantes do centro, onde surgem "aglomerados urbanos de exclusão". Essas áreas são dimensões geográficas que representam também formas precárias de territórios que constituem espaços de resistência pelo direito à moradia, mas por outro lado, convivem com problemas de infraestrutura urbana. É assim então que, em meio à precariedade urbana, o narcotráfico oferece uma forma perversa de integração relacionada à economia do crime.

Por fim, o trabalho mostrou as duas formas de organização espacial do narcotráfico encontradas em Belém. São lógicas territoriais reticulares e zonais. Uma define-se como territórios-rede ou territórios em redes e a outra destaca-se como territórios-zona ou territórios em zonas. Com efeito, Belém está conectada a uma rede de relações organizacionais da economia do crime, pois a cidade é um dos nós das redes do narcotráfico na Amazônia e faz parte de uma teia complexa e estruturada de relações globais e locais que articulam a movimentação dos fluxos que alimentam o "mercado da droga".

\section{REFERÊNCIAS}

BARNES, J.A. Social Networks. Cambridge: Module 26, p.1-29, 1972.

CASTELLS, Manuel. O fim do milênio. São Paulo: Paz e Terra, 1996.

A sociedade em rede. São Paulo: Paz e Terra, 1999. v. 1.

COLONOMOS, Ariell. Emergence d'un objet et perspectives internacionalistes. In.: CHARILLON, Frederic. et al. Sociologie des réseaux transnationaux. Paris: Editions L'Harmattan, 1995. 299p.

DELEUSE, Gilles e GUATTARI, Félix. (s/d). O Anti-Édipo: capitalismo e esquizofrenia. Lisboa, Assírio \& Alvim, p. 261.

FOUCAULT, Michel. Vigiar e punir. Petrópolis: Gallimard, 1975.

Microfísica do poder. Rio de Janeiro: Graal, 1979.

História da sexualidade: a vontade de saber. Trad. Maria Thereza da costa Albuquerque e J.A. Guilhon Albuquerque. Rio de Janeiro: Edições Graal, 1988.

Em defesa da sociedade. Trad. Maria Galvão. São Paulo. Editora: Martins Fontes, 2008.

Segurança, território, população. Trad. Eduardo Brandão. São Paulo: Martins fontes, 2008.

HAESBAERT, Rogério. Desterritorialização: entre as redes e os aglomerados de exclusão. In: CASTRO, I. et al. (Org.). Geografia: conceitos e temas. Rio de Janeiro: Bertrand Brasil, 1995.

O mito da desterritorialização: do fim dos territórios à multiterritorialidade. Rio de Janeiro: Bertrand Brasil, 2004.

HAESBAERT, R. Des-territorialização e identidade: a rede "gaúcha" no Nordeste. Rio de Janeiro: EDUFF, 1997. 
Evolução e configuração geográfica dos territórios do tráfico de drogas na periferia de Belém

IBGE. Censo Demográfico 2010. Aglomerados subnormais: primeiros resultados. Rio de Janeiro: IBGE, 2010. Disponível em: Acesso em: 09 mai. 2020.

MARTINS, José de Souza. Exclusão social e a nova desigualdade. São Paulo: Paulus, 1997.

A sociedade vista do abismo. 2. ed. São Paulo: Vozes, 2002.

DELEUSE, Gilles e GUATTARI, Félix. (s/d). O Anti-Édipo: capitalismo e esquizofrenia. Lisboa, Assírio \& Alvim, p. 261.

Texto recebido em: 01/07/2019

Texto aprovado em: 11/06/2020 